\title{
Research on the Influence of Physical Exercise on Students' Academic Achievement
}

\author{
Nan Wan ${ }^{1,}$ a Lu Wan ${ }^{1, \text { a }}$ \\ ${ }^{1}$ Jiangxi Science and Technology Normal University, JiangXi, Nanchang, 330013 \\ ${ }^{2}$ Nanchang Teachers College, JiangXi, Nanchang, 330103 \\ aemail, bemail,
}

Keywords: Physical Exercise, Student, Student Achievement

\begin{abstract}
In this paper, the effects of physical exercise on the academic performance of primary school students, middle school students and college students are expounded using logical analysis and literature quality method. It found that the number of domestic research is not enough and not systematic, while foreign research, although rich and profound, but mostly one-on-one straight line study, ignoring the broader research areas. Therefore, the study of the impact of physical exercise on the academic performance of students must be based on the results of quantitative experiments to enhance the scientific nature of the study to explore the scientific exercise program to encourage students to participate in physical exercise and then comprehensive and sustainable development.
\end{abstract}

\section{Introduction}

As early as thousands of years ago, physical exercise has emerged and has an indispensable role in the development of human society. Leader Chairman Mao once in the "new youth" published a sensation Changsha academy's "sports research", the article talked about the sports to enhance physical fitness, save the survival of the important significance, but with the economic and social development and the growing popularity of the network, sports have been increasingly ignored, due to various practical factors, sports are set at the end of the teaching system. This paper examines the impact of physical exercise on student academic performance, aims to change the traditional view of physical exercise, highlighting the importance of physical exercise in modern education.

\section{The Main Research Methods}

The Literature Method. In the Wanfang database, China Knowledge Network, Wikipedia and Baidu Encyclopedia, "physical exercise" and "student academic performance" into keywords, a total of out of the journal papers and doctoral thesis 109, of which a total of 90 Chinese, a total of 19 English, and in a university library borrowed seven academic monographs. These literatures provide a rich theoretical basis for the author's research.

Logical Analysis. This paper summarizes the influence of physical exercise on the academic achievement of the students, and explores the loopholes in the research of the present stage, and then puts forward the main research direction in the future.

\section{The Impact of Physical Exercise on the Academic Performance of Students at All Stages}

The Impact of Physical Exercise on the Academic Performance of Primary School Students. After entering this century, the study on the impact of physical exercise on student academic performance began to mature. In 2007, the scholar Somerset B.S. will be 214 primary school sixth grade students as the object of study, the students were randomly divided into observation group and control group two groups, observe the class to teach sports, the other class of cultural knowledge. After a semester, compare the academic performance of the two classes. Found that classroom physical education on the student's academic performance did not have a significant impact, and 20 minutes a day out of the activities of the students will have a significant impact on academic performance. The study of this problem has also been refined into a particular discipline 
and compared the different aspects of the impact. The following year, the scholar Stevens TA conducted 3226 girls and 3167 boys in the US primary school in Texas as subjects, investigated the family background and academic level of the students, and recorded the physical activity of the students as well as the physical education exercise intensity, summed up the students after the physical exercise of academic performance. After analyzing the data, it was found that physical exercise helped to improve the reading level and math scores of primary school students, while the physical education courses offered by schools did not have a significant impact on the improvement of academic achievement [1].

The Impact of Physical Exercise on the Academic Performance of Secondary School Students. In the various age groups of students, secondary school academic performance differences are more prominent, more volatile. And because of the growth and development period, and other age groups of students compared to the implementation of physical exercise is particularly important.

In 2003, Guest A. selected 6458 high school students in the United States as the object of study, and launched a questionnaire survey in-depth analysis of the results obtained from the academic staff of these students found that physical exercise can be effectively promoted student's academic performance. At the same time, the physical environment in the process of physical exercise and the natural environment, the types of training programs and the intensity of the exercise will have different degrees of academic performance. It also from the psychological point of view, elaborated on the desire for physical exercise will also have a positive impact on academic performance. The results show that under the premise of the same physical exercise, different students to exercise the enthusiasm of the high degree of academic performance will have a different impact.

Physical exercise can promote human growth and development which is obvious to all, then the health of the academic performance will have a certain impact? The answer is inevitable. Now more and more scholars have attached great importance to this issue. In 2010, Welk GJ and other scholars use the school academic performance scale and physical quality scale, the US Texas middle school students in the academic level and physical health were tested and found that students will be with academic performance Improve the degree of physical health and enhance. I think that through physical exercise to improve their own health status, in the future research links can be the health situation as physical exercise and academic performance of the intermediate variables, systematic research.

The Impact of Physical Exercise on College Students' Academic Performance. Students are a special group of students, students enter the university, the study and life more relaxed, you can arrange a reasonable time, in the physical exercise can also bet more energy, the individual difference between the obvious. Therefore, the impact of its physical exercise on the academic performance of the exploration is of great significance. In 1993, the scholar Maloney M. T. collected a large number of students in the academic situation, comparative study of university athletes and ordinary college students between the academic performance and the results show that ordinary college students' academic performance more rational, which with our traditional ideas confirmed each other. It can be seen that the amount of exercise is too large, too long exercise time may also have a negative impact on the student's academic performance.

In 1994, scholar Jacobs J. P. et al. Conducted a four-month experiment on 121 baseball players in eight US colleges and universities to explore the relationship between exercise and academic performance. Athletes were randomly assigned to one of the three groups, and only one group did not establish physical activity and academic goals. The end result of the experiment shows that building physical activity and academic performance goals can help to optimize students' academic performance. Maloney M. T. and Jacobs J. P. all attach great importance to the correlation between exercise and academic performance. The former emphasizes the definition of reasonable exercise, while the latter emphasizes the establishment of physical and academic goals to promote academic progress. In the future, Chinese athletes’ culture course learning can be a certain referral [2]. 


\section{The Current Research Lack and Future Research Trends}

The Shortcomings of the Current Study. In recent years, although the international study on the impact of physical exercise on student academic performance is very rich, but most of the research on the influencing factors is one-on-one straight line study, ignoring a broader field of research. So it should be more to rely on physical fitness, execution and intelligence and other intermediate variables, to explore its multiple influencing factors. In addition, the lack of long-term follow-up research in this field, the longest study period is less than two years, and other disciplines is difficult to the same day.

Finally, although the number of research in the field of research continues to rise, it has not reached a high degree of theoretical level. There are a lot of theory is only foreign scholars in the experiment after the ideas and speculation, it is difficult to produce more authoritative theoretical results. Compared with foreign countries, domestic research is very fragmented and the lack of a comprehensive and systematic inquiry, the experimental point of view not only old-fashioned new ideas, and the content is simple.

Future Research Trends. In the course of the future research process, we should fully combine the experimental results and research conclusions, to explore each of the sports on the academic performance of the different effects, and then developed for all ages and different physical fitness program, and In the actual application of continuous optimization and improvement, to enhance its operational, close to the actual needs of students, to promote the comprehensive development of students moral and intellectual.

In addition, we need to establish a diversified research system, based on the quality of education, but also pay attention to the improvement of students' physical fitness and the basic structure of various disciplines, absorb the new achievements of modern science and technology from the macro and micro different levels, the establishment of this study is closely related to the composition of the subject group, academic structure and knowledge system [3].

\section{Conclusion}

In summary, at this stage of our country's sports is in a high-speed development stage, the student group is the main force of physical exercise. As the pillars of the country, to enhance the physical fitness of the overall quality of the overall improvement of the people has important practical significance. In this context, we must attach great importance to the physical activity of students to promote academic performance, change the traditional view of sports and the school should also pay great attention to sports, design a scientific and reasonable physical exercise program.

\section{References}

[1] Zhang Weixia, Jiao Yingying, Xu Xia, etc. The impact of high school students on academic performance - the mediating role of sleep quality[J]. Journal of Physical Education, 2016, 23 (6): 135-140.

[2] Wen Xu. Effects of physical exercise on adolescents' cognitive ability and academic performance: the history, present situation and future of research [J]. Journal of Sports Science, 2015, 10 (3): 73-82.

[3] Lu Yanwen, Zhu Jiahua.Study on the relationship between college students' physical exercise and academic achievement [J]. Journal of Sports Science and Technology Bulletin, 2017,25 (2): 63-64. 